\title{
Politik Kutuplaşma ve Gelirin Kişisel Dağılımı
}

\author{
Sacit Hadi AKDEDE* $\quad$ Nazlı KEYİFLİ**
}

\begin{abstract}
$\ddot{O} Z$
Bu çalışmada, politik kutuplaşmanın belirleyicileri ampirik olarak incelenmektedir. Devletin ekonomik büyüklüğ̈̈ ve gelir dağılımı ve diğer kontrol değişkenleri bağımsız değişkenleri oluşturmaktadır. Istatistiksel analiz olarak EKK ve 2EKK yöntemleri kullanılmıştır. Çalışma kapsamına 61 ülke dahildir ve 1990 ile 2015 arasındaki zaman aralı̆̆ kullanılmıştır. Regresyon analizi sonuçları, gelir eşitsizliğinin artmasının politik kutuplaşmayı arttırdığını gösteriyor. Politik kutuplaşma, Dünya Değerler Araştırması'ndan (WVS) elde edilmiştir. Söz konusu değişken "government responsibility" sorusuna verilen yanıtların standart sapması olarak ölçülür. Ek olarak, bizim ampirik sonuçlarımı hükümet büyüklüğ̈̈nün artmasının politik kutuplaşmayı azalttığına işaret ediyor. Çalışma bu bulguların bağlantılarını açıklamaktadır.
\end{abstract}

Anahtar Kelimeler: Politik Kutuplaşma, Kamu Büyüklüğü, Gelir Dă̆ılımı

JEL Sinıflandırması: H50, P16,D31

\section{Political Polarization, Income Inequality and Government}

\begin{abstract}
This paper empirically investigates the determinants of political polarization. Size of government and income distribution are the main independent variables along with other controlling variables. The statistical analysis uses OLS and 2SLS methodogies. The sample of countries includes 61 countries and time period spans between 1990 and 2015. Results of regressions analysis indicate that increased income inequality increases political polarization. Political polarization is derived from World Values Survey (WVS). It is measured as standard deviation of responses to the question "what is role for government". In addition, results of our empirical analysis indicates that increased governemt size reduces the political polarization. The paper explains the links for these findings.
\end{abstract}

Key Words: Political Polarization, Size of Government, Income Inequality

JEL Classification: H50, P16,D31

\section{GíRIŞ}

Son y1llarda ekonomi ve siyaset bilimlerinde politik kutuplaşmanın, hükümetler ve yasama organlarında siyasi karar alma süreçlerini etkileyebilmesinden dolayı önemli politik sonuçlar doğurduğu görülmektedir (Lindqvist ve Östling, 2010: 543; Campante ve Hojman, 2013: 91). Örneğin, politik kutuplaşmanın ekonomik performansı, maliye politikasını (Lindqvist ve Östling, 2010), yasama verimliliğini (Hacker, 2004), gelir eşitsizliğini (McCarty vd., 2006; Meltzer \& Richard 1981) ve ekonomik kalkınmay1 (Frye, 2002) önemli ölçüde etkilediği görülmektedir. Ayrıca, politik kutuplaşma, bir toplumdaki ekonomik gelişmişlik seviyesine bağlı olmanın yanında, politik

\footnotetext{
* Prof. Dr. İzmir Bakırçay Üniversitesi, İIBF, İktisat, İktisat Teorisi, sacithadi.akdede@bakircay.edu.tr

*** Dr. Öğr.Üyesi, Gümüşhane Üniversitesi, İ̈BF, Maliye, Bütçe ve Mali Planlama, nazlikeyifli@gumushane.edu.tr
} 
konulardaki tutumların farklılık derecesini de yansitmaktadır (Grechyna, 2016: $10)$.

Politik kutuplaşma, gelişmiş ve gelişmekte olan pek çok ülkede toplumsal ve siyasi huzursuzluk ile yakından ilişkilidir (Montalvo ve Reynal-Querol, 2005:301). Dolayısıyla, devlet maliye politikası araçlarını kullanarak toplumdaki sürtüşmeleri en aza indirmeyi başarabilir (Lindqvist ve Östling, 2010: 543). Örneğin, hükümetler, gelirlerinin önemli bir bölümünü eğitim, sağlik ya da altyap1 gibi kamu malları üzerine harcayarak toplumun politikacılara karşı olumsuz tutumunu ve politik kutuplaşmayı azaltabilir (Grechyna, 2016: 11).

Öte yandan, politik kutuplaşmanın, koalisyon hükümetlerinde ya da çok partili yasama organlarında, yoksul, etnik olarak ayrışmış, güven düzeyinin düşük, gelir eşitsizliğinin yüksek olduğu ülkelerde daha üst düzeye tırmandığg görülmektedir (Lindqvist ve Östling, 2010; Grechyna, 2016). Kutuplaşmanın yüksek olduğu ülkelerde kutuplaşmanın az olduğu ülkelere kıyasla bütçe açıkları biraz daha fazladır ve ekonomik eşitsizlik oldukça büyüktür (Alt ve Lassen, 2006: 541). Ayrıca, politik kutuplaşma sadece kutuplaşmış siyasete değil, liberal ve muhafazakârların gittikçe birbirinden uzaklaştığı bölünmüş bir topluma da işaret eder (Piereson, 2015). Bu anlatılanlar çerçevesinde, ampirik araştırmalar kutuplaşmanın (siyasi ve sosyal) genel itibarıla hükümet politikaları üzerinde olumsuz etkileri olduğunu vurgulamaktadır (Testa, 2012: 1104). Ancak, bazı demokratik ülkelerdeki kutuplaşma, önemli faydalar sağlayabilmektedir. $\mathrm{Bu}$ durum, ülkelerin uyguladıkları kurumsal düzenlemelere bağlı olarak kutuplaşmayı verimli bir şekilde ele almaya izin vermektedir (Alesina ve La Ferrara, 2005: 774).

Politik kutuplaşmanın genel olarak toplumsal huzursuzluğun varlığıyla ve siyasi ve sosyal alanda yaşanan çatışmalarla bağlantılı olmasının (Estaban ve Ray, 2011: 1345) yanı sıra ekonomi literatüründe kabul görmüş bir tanımı bulunmamaktadır (Akdede, 2012: 20). Kutuplaşma kavramı genel itibarıyla toplumdaki bireylerin, nüfusun bazı özelliklerine göre kümeler halinde gruplanabileceğini ifade etmektedir. Yani, kutuplaşma en az iki grubun varlığını ifade eder. Dolayısıyla, gruplar içinde eşitsizlik azaldığında ya da gruplar arasında arttığında kutuplaşma artar. Böyle bir durumda, her kümenin mensubu nitelik bakımından benzerdir ancak farklı kümelerin benzer olmayan niteliklere sahip üyelerden oluştuğunu varsaydığımızda toplumun kutuplaşmış olduğunu söyleyebiliriz. Toplumdaki bireyleri belli kümeler halinde gruplandıran özellikler, gelir ve servet olabileceği gibi siyasi ideoloji de olabilmektedir. Söz konusu gruplanmalarda her bir grubun kendi içinde yüksek düzeyde homojenliğe sahip olması ve gruplar arasında ise yüksek düzeyde bir heterojenlik bulunmas gerekmektedir (Esteban ve Ray, 1994: 819-824). Esasen kutuplaşma, kümelenmelerin ya da grupların oluşumu olarak da görülebilir (Akdede, 2012: 21).

Literatüre bakıldığında kutuplaşmanın farklı şekillerde ele alınabileceği ve oluşturulan endekslerin ortaya konulan faktörlere de bağlı olduğu 
görülmektedir. Bu bağlamda, politik kutuplaşmanın ölçümü konusunda alternatif yöntemler ortaya çıkmıştır (Bkz. Esteban ve Ray, 1994; Duclos vd.,2004; Lindqvist ve Östling, 2010; Grechyna, 2016). Bu çalışmada politik kutuplaşmayı hesaplamak için Lindqvist ve Östling (2010) ve Grechyna, (2016) çalışmalarında yararlandıkları seçmenlerin kendi iradeleri doğrultusunda bildirdiği siyasi tercihlere dayanan ölçüm değeri kullanılmıştır. Bu, Dünya Değerler Anketi (WVS) veri tabanında bulunan "government responsibility" anket sorusunun standart sapmasıyla hesaplanan ölçüm değeridir. WVS, beş yılda bir dönemler (waves) halinde gerçekleştirilen ve ulusal olarak temsil edilen anket sorularından oluşur ve ülke başına yaklaşık 1.000 kişiyle yapılan yüz yüze görüşmelere dayanılarak ulaşılan cevapları içerir.

Şüphesiz, kutuplaşmanın analizi ekonomik ve politik bir öneme sahiptir. Kutuplaşmış bir sistemin ekonomik nedenlerini anlamak, politika yapıcılara eşitsizlikleri azaltmak adına uygulayabilecekleri politikalar konusunda yol gösterici olabilmektedir (Azomahou ve Diene, 2012). Bu nedenle, çalışmada politik kutuplaşmanın belirleyicileri ortaya konulmaya çalışılmıştır. Çalışma, giriş ve sonuç bölümleri dâhil beş bölümden oluşmaktadır. Bu doğrultuda, çalışmada ilk olarak politik kutuplaşmanın belirleyicileri ele alınmış ardından konuya ilişkin literatüre yer verilmiş ve sonrasında ampirik uygulamaya geçilmiştir. Söz konusu bölümde kullanılan veri seti, model, yöntem ve ampirik bulgular yer almaktadır. Sonuç ve ampirik bulguların değerlendirilmesi ile çalışma son bulmaktadır.

\section{I.POLITIK KUTUPLAŞMA VE BELIRLEYİCİLERİ}

Bir ülkede yer alan farklı etnik, dini ve kültürel anlayışlardan beslenen politik kutuplaşma farklı siyasi tercihleri ortaya çıkarabilmektedir. Özellikle, son zamanlarda ekonomi ve siyaset bilimindeki ampirik araştırmalar, çeşitli kutuplaşma şekillerinin devletlerin kendi içinde ve birbirleri arasında şiddetli çatışma riskini arttırdığını göstermektedir (Azomahou ve Diene, 2012:422). Bu bağlamda, sosyo-tarihsel ve ekonomik bir olgu olan politik kutuplaşmanın potansiyel belirleyicilerini ortaya koymak politika yapıcılar ve kamusal karar alıcılar için önem taşımaktadır. Aşağıda politik kutuplaşmanın belirleyicileri açıklanmaya çalışılmıştır.

Gelir Eşitsizliği: Gelir dağılımı, toplumun sosyo-kültürel yapısından, nüfus artışından ve dağılımından etkilenen ekonomik bir olgudur (Çakır, 2002: 91). Politik kutuplaşma ve gelir eşitsizliği ise dağılımın farklı yönlerini vurgulasalar da yakından ilişkili kavramlardır. Örneğin, iki farklı gelir grubuna ayrılan bir örneklemde, sadece bir grubun eşitsizliğinin azaltılması durumu daha büyük bir politik kutuplaşmaya neden olabilmektedir (Azomahou ve Diene, 2012:422). Bu durum, literatürde politik kutuplaşma ve gelir eşitsizliği ilişkisinde en sık tartışılan konulardan biri haline gelmiştir. Çalışmada, gelir eşitsizliğini ölçmek için yeniden dağıtım sonrası gini katsayısı kullanılmıştır.

Kişi Başı Gayri Safi Yurtiçi Hasıla (GSYIH) : Bu değişken bir ülkenin ekonomik gelişme düzeyini temsil etmektedir. Yani, ekonomik performansın en yaygın ölçüsü olan GSYİH aynı zaman da demokratik kurumların ortaya çıkmasını teşvik eden önemli bir faktördür (Londregan ve Poole, 1996:3). Bu 
çalışmada, politik kutuplaşmanın kısmen de olsa bir ülkenin ekonomik koşullarına göre belirlenip belirlenmediği araştırılmak istenmiştir. GSYİH'nın politik kutuplaşmayı azaltması beklenmektedir.

Kamu Harcamaları: Kamu harcamalarının etkin bir iktisat politikası aracı olarak kullanılabilmesi devletin ekonomi alanındaki başarısını etkiler. Dolayısıyla, kamu harcamaları, toplumdaki politik tercihleri ve bu tercihlerin sonucunu da etkileyebilmektedir. Örneğin, hükümetler toplanan gelirin önemli bir payını eğitim, sağlık ve alt yapı gibi kamu mallarına harcayarak toplumdaki politikacılara yönelik olumsuz tutumu ve kutuplaşmayı azaltabilir (Grenhyna, 2016: 11). Dolayısıyla kamu kesiminin büyüklüğü birçok ekonomik değişkeni etkilediği kadar politik sürtüşmeleri yani politik faktörleri de etkilemektedir (Lindqvist and Östling, 2010: 554). Çalışmada, kamu kesimi büyüklüğünü ölçmek için kamu tüketim harcamalarının GSYİH'ya oranı kullanılmıştır.

Sosyal Çeşitlilik : $\mathrm{Bu}$ değişken, bir çok ülkenin ve bölgenin politik ekonomisinin önemli belirleyicilerinden biridir ve davranışların politik meselelere dağılımını etkileyecek kültürel çeşitliliği açıklar (Alesina, vd., 2002: 156). Esteban ve Ray (2011), bir ülkede kutuplaşma ve eşitsizliğin belirleyicileri arasında söz konusu sosyal çeşitlilik değişkenini de kullanmışlardır. Ayrıca, Akdede (2010), dini çeşitliliğin daha yüksek bir demokratikleşmeye neden olduğunu öne sürmüştür. Bu çalışmada sosyal çeşitlilik için dini çeşitlilik kullanılmıştır.

Demokrasi Seviyesi : Demokratikleşme veya siyasi rejim değişikliği, politik süreç içerisinde çeşitli kurumsal değişikliklere sebep olduğundan kamu politikalarını büyük oranda etkileyebilmektedir (Profeta vd., 2013: 685; Kotera ve Okada, 2017: 145). Demokratik toplumlar politik tutumlarını ortaya koyma ve tartışma konusunda daha fazla özgürlüğe sahiptir. Böylelikle, demokrasiler, insanlara oy kullanma hakkı ile kamu politikaları konusundaki tercihlerini oylama ve ifade etme imkanı sunmaktadır (Profeta vd., 2013: 686). Çalışmada demokrasinin ölçüsü olarak, -10 ile +10 arasında değişen değerler alan Polity IV göstergesi kullanılmışıtır. -10 demokrasi yok anlamına, +10 da yüksek seviyede demokrasi var anlamina gelmektedir.

Politik kutuplaşmaya sahip en düşük ilk 10 ve en yüksek ilk 10 ülke sıralaması Tablo 1'de sunulmuştur. Tabloda görüldüğü üzere, Pakistan, Irak, Ruanda ve İsveç gibi politik kutuplaşmanın düşük olduğu ülkelerde, insanların bireyci davranma eğilimlerinin azaldığı ve devlete daha fazla görev yüklediği varsayılmaktadır. Meksika, Türkiye ve Hindistan gibi ülkelerde ise politik kutuplaşmanın yüksek olduğu görülmektedir. 
Yönetim ve Ekonomi 27/2 (2020) 337-351

Tablo 1: En Düşük ve En Yüksek Politik Kutuplaşmaya Sahip Ülkeler

\begin{tabular}{cccc}
\hline En Düşük & Kutuplaşma & En Yüksek & Kutuplaşma \\
\hline \hline Pakistan & 1.92 & Zimbabve & 3.29 \\
Irak & 1.99 & Kolombiya & 3.3 \\
Ruanda & 2.08 & Arjantin & 3.35 \\
İsveç & 2.1 & Romanya & 3.42 \\
Hollanda & 2.12 & Bangladeş & 3.43 \\
Gürcistan & 2.15 & Venezuela & 3.46 \\
Norveç & 2.21 & Brezilya & 3.47 \\
Fas & 2.24 & Güney Afrika & 3.5 \\
Misır & 2.24 & Hindistan & 3.52 \\
Finlandiya & 2.31 & Türkiye & 3.6 \\
Estonya & 2.32 & Meksika & 3.6 \\
\hline
\end{tabular}

Kaynak: Dünya Değerler Anketi (WVS), wave2, wave3, wave3, wave4, wave5, wave5, wave6 verileriyle oluşturulmuştur.

\section{LITERATÜR}

Yapılan literatür incelemesinde, kutuplaşma konusunu ampirik olarak araştıran az sayıda çalışma olduğu görülmektedir. Bunun temel nedeni, politik kutuplaşma değerinin istatistiksel olarak kolay ölçülemediği gerçeğidir. Bildiğimiz kadarıyla Türkiye özelinde politik kutuplaşmayı WVS verileri yardımıyla ölçen bir çalışma olmaması dolayısıyla, bu çalışmada var olan boşluğun doldurulması amaçlanmaktadır.

Kutuplaşma konusuna ilişkin çalı̧̧malardan birkaçına değinecek olursak; Zhang ve Kanbur (2001), 1983-1995 dönemleri için Çin'nin 30 vilayeti üzerine yaptıkları çalışmada farklı kutuplaşma endeksleri kullanmalarına rağmen gelir dağılımında belirgin bir farklılaşma olmadığını tespit etmişlerdir.

Duclos vd. (2004), 1989-1997 dönemi için Lüksemburg Gelir Araştırması veri tabanından yararlanarak 21 ülkenin verilerini kullanarak gelir kutuplaşması ölçüsü oluşturmaya çalışmışlardır. Kutuplaşma ve eşitsizlik sıralamalarının çoğu zaman farklı olabileceği sonucuna ulaşmışlardır.

McCarty vd. (2003, 2006), 1952-2000 ve 1973-2004 dönemleri için Ulusal Seçim Çalışması (NES) verilerini kullanarak ABD eyaletleri üzerine yaptıkları çalışmalarında gelir eşitsizliği ve partizan politikalar arasındaki ilişkiyi ampirik olarak araştırmışlardır. Analiz sonucuna göre, hem seçmenleri hem de hükümette bulunan siyasi partileri gelir dağılımı eşitsizliğinin yüksek olduğu dönemlerde ideolojik olarak kutuplaştığ 1 görülmüştür. Kısacası, eşitsizlik ve kutuplaşmanın paralel olarak arttığ 1 sonucuna ulaşmışlardır.

Pontusson ve Rueda (2008), 1970'ler, 1980'ler ve 1990'lar dönemi için OECD ülkelerinin verilerini kullanarak gelir eşitsizliğinin parti politikaları üzerindeki etkisini araştırmışlardır. Sol partilerin sağ partilere göre yeniden dağıtımda daha fazla rol oynadığı sonucuna ulaşmışlardır.

Lindqvist ve Östling (2010), politik kutuplaşma ve devletin boyutu arasındaki ilişkiyi incelemişlerdir. Söz konusu çalışmada, 74 ülkenin 1995-2005 dönemine ait verilerinden yararlanarak politik kutuplaşma ve devletin boyutu 
arasındaki ilişkiyi açıklamaya çalışmışlardır. Politik kutuplaşma ve devletin boyutu arasındaki ilişkinin demokratik ülkelerde ve eğer devletin boyutunun küçükse güçlü olduğu ancak antidemokratik ülkelerde ise bu ilişkinin olmadığını görmüşlerdir.

Garand (2010), 1972-2004 dönemine ait ABD eyaletlerinin verilerini kullanarak yaptığı çalışmasında politik parti kutuplaşması ve gelir eşitsizliği arasındaki ilişkiyi panel veri yöntemi kullanarak araştırmıştır. Gelir dağılımı eşitsizliğinin yüksek olduğu eyaletlerde kutuplaşmanın yüksek olduğu sonucuna ulaşmıştır.

Rehm (2011), ABD'nin 1971-2002 dönemine ait verilerini kullanarak yaptığ 1 çalışmasında, ABD siyasetinde 1970 'den bu yana partizancılığın artış nedenini araştırmıştır. Yazar, bireylerin partizan tercihlerinin yalnızca geleneksel olarak önerilen sosyo-ekonomik faktörler tarafından şekillendirilmediği, gelecekteki gelirin belirsizliğinin söz konusu tercihleri üzerinde güçlü bir faktör olduğu sonucuna ulaşmıştır. Ayrıca, elde edilen bir diğer sonuç da Amerikan seçmenlerinin gelir beklentilerinin Demokratlara sempati duymalarına yol açtığıdır.

Brown, vd. (2011), 125 ülke üzerine yaptıkları çalışmalarında 1996-2008 dönemi ele alınmış olup yolsuzluk ve ideolojik kutuplaşma arasındaki ilişki panel veri analizi yöntemiyle araştırılmıştır. Elde edilen sonuçlara göre ideolojik kutuplaşmanın yolsuzluğu tetiklediği öngörülmüştür.

Akdede (2012), 17 Avrupa ülkesi için 1980'ler, 1990'lar ve 2000'ler verilerini kullanarak ekonomik eşitsizlik ile politik kutuplaşma ve siyasi ayrışma arasındaki ilişkiyi ampirik olarak incelemiştir. Artan gelir eşitsizliğinin siyasi parti kutuplaşmasını arttırdığ 1 ve siyasi ayrışmayı azalttığı ve siyasi parti kutuplaşmasının kişi başına düşen GSYİH ile azaldığı gösterilmiştir.

McCright, vd. (2014), ABD üzerine 1974-2012 dönemi için genel sosyal anket verilerini kullanarak mevcut hükümetlerin çevreyi korumaya yönelik harcamalarını incelemişlerdir. Çalışmada 1992'den bu yana çevre harcamalarına destek konusunda ideolojik kutuplaşmanın etkili olduğu görülmüştür. Dolayısıyla kutuplaşmadaki artışın çevre politikalarını çevre dostu davranışların yayılmasını engelleyeceği varsayılmaktadır.

Grechyna (2016), 66 ülkenin 1990-2013 dönemine ait verileri kullanarak politik kutuplaşmanın belirleyicilerini ampirik olarak araştırmıştır. İnsanlar arasındaki yüksek güven ve gelir dağılımı eşitsizliğinin azalması politik kutuplaşmayı azalttığı ve kamu harcamaları ve kişi başı GSYİH'nın politik kutuplaşmayı azaltan diğer önemli faktörler arasında olduğu sonucuna ulaşmıştır.

Literatür özeti bölümünde de görüldüğü gibi kimi çalışmalarda politik kutuplaşmanın nedenleri kimi çalışmalarda da sonuçları incelenmiştir. Bu çalışmada politik kutuplaşmayı etkileyen, belirleyen faktörler araştırılacaktır. Bundan sonraki bölümde istatistiksel analize yer verilecektir. 


\section{EKONOMETRIKK METODOLOJİ VE BULGULAR}

\section{A. Veri Seti}

$\mathrm{Bu}$ çalışmada, WVS veri tabanında yer alan $61^{1}$ ülkenin 1990-2015 dönemine ait 5'er y1llık ortalama verileri kullanılarak politik kutuplaşmayı etkileyen faktörler ortaya konulmaya çalışılmıştır. Veri setinin 5'er yıllık oluşturulmasının nedeni politik kutuplaşma verisinin 5'er yıllık düzenleniyor olmasıdır. Ayrıca, çalışmada belirtilen dönem ve ülkeler, Dünya Değerler Anketi (WVS) veri tabanından verilerin elde edilebilirliğine göre seçilmiştir. Ancak, ele alınan bu ülkeler sosyo-ekonomik ve demografik özellikleri, coğrafi koşulları ve diğer pek çok açılardan farklı özellikler sergilemekte olup heterojen bir yapı göstermektedir.

Çalışmada kullanılan ülke verileri Dünya Bankası (World Bank), Dünya Değerler Anketi (World Values Survey-WVS), The Quality of Government Dataset, Marshall and Jaegger's Polity's 4 Dataset ve LaPorta vd. (1999) veri tabanlarından elde edilmiştir. Modelde kullanılan değişkenlere ilişkin bilgiler Tablo 2'de gösterilmektedir.

Tablo 2: Çalışmanın Veri Seti

\begin{tabular}{|c|c|c|c|}
\hline Değişken Türü & Değişkenin $A d l$ & Kisaltması & Kaynağı \\
\hline \multirow[t]{3}{*}{ Bağımlı Değiş̧ken } & Politik Kutuplaşma & $\bar{K}$ & World Values Survey \\
\hline & Gelir Eşitsizliği (Gini) & Gini & \\
\hline & Kişi Başı GSYİH & G & Dünya Bankası (WB) \\
\hline \multirow{3}{*}{ Bağımsız Değişken } & Kamu Tüketim Harcaması & $\mathrm{T}$ & \\
\hline & $\begin{array}{l}\text { Sosyal Çeşitlilik (Religious } \\
\text { Fractionalization) }\end{array}$ & Ç & $\begin{array}{c}\text { The Quality of Government } \\
\text { Dataset }\end{array}$ \\
\hline & Demokrasi Seviyesi & $\mathrm{D}$ & $\begin{array}{l}\text { Marshall and Jaegger's } \\
\text { Polity's } 4 \text { Dataset }\end{array}$ \\
\hline Kukla Değişken & Gelişmekte Olan Ülke & $\mathrm{Ge}$ & Dünya Bankası (WB) \\
\hline Araç Değişsken & $\begin{array}{c}\text { Hukuk Sistemleri (İngiliz, } \\
\text { İskandinav, Ango-Sakson, } \\
\text { Fransı) }\end{array}$ & & LaPorta vd. (1999) \\
\hline
\end{tabular}

Politik kutuplaşma olan bağımlı değişkenimiz standart sapma şeklinde kullanılmıştır. Söz konusu değişkenin (politik kutuplaşma) rakamsal değeri için Dünya Değerler Anketi (World Values Survey) veri tabanında bulunan "government responsibility" anket sorusunun standart sapmasiyla hesaplanan ölçüm değeri kullanılmıştır. Çalışmada kullanmış olduğumuz "government responsibility" anket sorusu 1 ila 10 ölçekte ölçülen değerler alır. 1'den 101a kadar giden ölçeklendirmede, bireylerin 1 ile 10 arasında bir değer seçmesi

\footnotetext{
${ }^{1}$ Arnavutluk, Cezayir, Arjantin, Ermenistan, Avustralya, Azerbeycan, Bangladeş, Belarus, Bosna, Brezilya, Bulgaristan, Kanada, Şili, Kolombiya, Kıbrıs, Çek Cumhuriyeti, Mısır, Estonya, Finlandiya, Gürcistan, Almanya, Gana, Macaristan, Hindistan, Endonezya, İran, Irak, Japonya, Ürdün, Kırgızistan, Makedonya, Malezya, Meksika, Moldova, Fas, Hollanda, Yeni Zelanda, Nijerya, Norveç, Pakistan, Peru, Filipinler, Polonya, Romanya, Rusya, Ruanda, Singapur, Slovakya, Slovenya, Güney Afrika, İspanya, İsveç, İsviçre, Tayland, Türkiye, Ukrayna, Amerika Birleşik Devletleri, Uruguay, Venezuela, Vietnam, Zimbabve.
} 
istenmektedir. Her ülkede bireylerin bu sorulara verdikleri yantlardan oluşan bir ortalama değeri ve bir de standart sapma değeri vardır. Ortalama değerler genellikle 5 civarında toplandığından iyi bir gösterge olmamaktadır. Bundan dolayı literatürde standart sapma değerleri politik kutuplaşma değerleri olarak kabul edilmektedir (Lindqvist ve Östling, 2010 ve Grechyna, 2016). Modelde kullanılan bağımsız değişkenlere bakıldığında; Gelir eşitsizliği için gini katsayısı kullanılmış olup Dünya Bankası veri tabanından elde edilmiştir. Gini endeksinde 0 mükemmel eșitliği 100 ise mükemmel bir eșitsizliği ifade etmektedir. Modelde sosyal çeşitlilik olarak dinsel çeşitlilik (religious fractionalization) kullanılmış olup bu değişken "The Quality of Government Dataset" veri tabanından elde edilmiştir. 0 ila 1 arasında değerler alır. 0 sosyal çeşitliliğin olmadığını 1 ise sosyal çeşitliliğin yüksek olduğu anlamına gelmektedir. Demokrasi değişkeni "Marshall and Jaegger's Polity's 4 Dataset" veri setinden elde edilmiştir. Değişken -10 ila +10 arasında değerler alır. -10 zayıf demokrasileri +10 ise güçlü demokrasileri ifade etmektedir. Bir diğer bağımsız değişken olan devletin ekonomik boyutunu ölçmek için kamu tüketim harcamalarının gayri safi yurtiçi hasılaya oranı dikkate alınmış ve söz konusu değişken Dünya Bankası veri tabanından temin edilmiştir. Çalışmamızda kişi başı GSYIH ve gelişmekte olan ülke değişkenleri Dünya Bankası veri tabanından elde edilmiştir.

Değişkenler arasındaki ilişkiyi veren serpilme diyagramında (Şekil 1) politik kutuplaşma ile gelir eşitsizliği arasında pozitif yönlü bir ilişkinin mevcut olduğu görülmektedir. Yani, bu diyagram, ele alınan ülke örnekleminde gelir eşitsizliği arttıkça politik kutuplaşma artmaktadır şeklinde önsel bilgi sunmaktadir.

Şekil 1: Politik Kutuplaşma- Gelir Eşitsizliği İlişskisi Serpilme Diyagramı

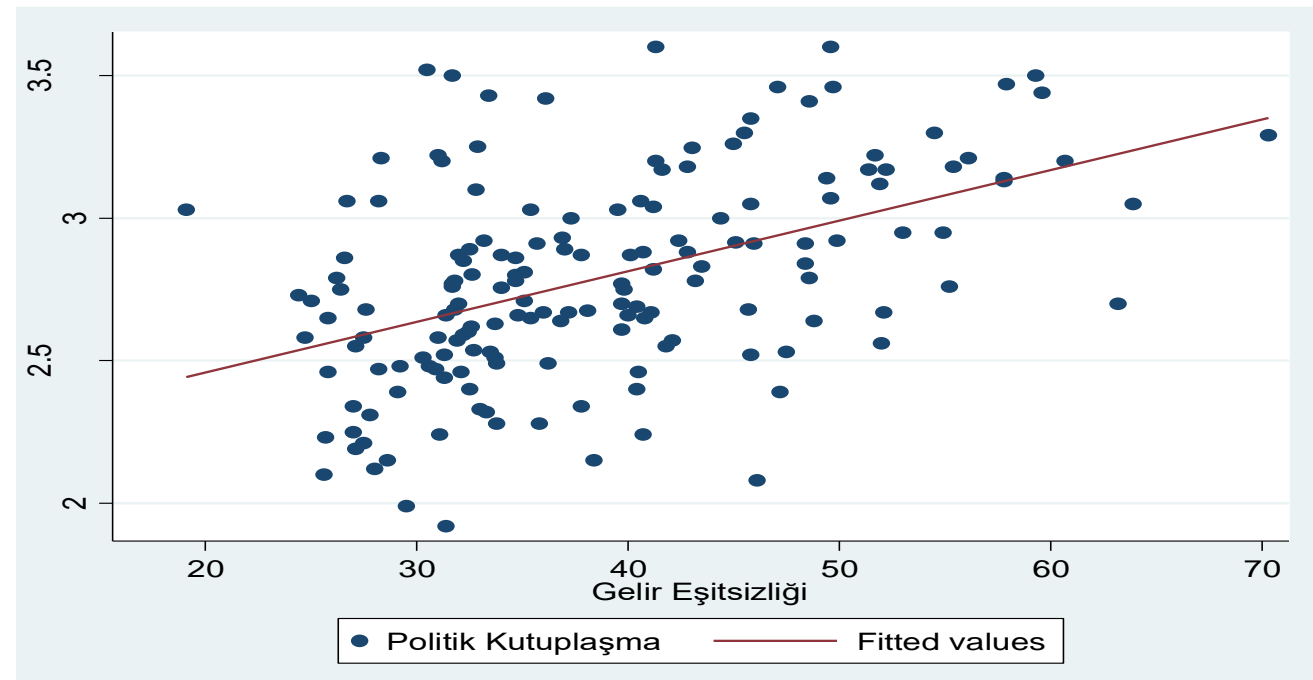

Ele alınan ülke örnekleminde 1990-2015 dönemine ait gelir eşitsizliğinin 5'er yıllık ortalamalarının değişimi Şekil 2'de verilmiştir. 
Yönetim ve Ekonomi 27/2 (2020) 337-351

Şekil 2: 1990-2015 Dönemi Gelir Eşitsizliğinin Gelişimi

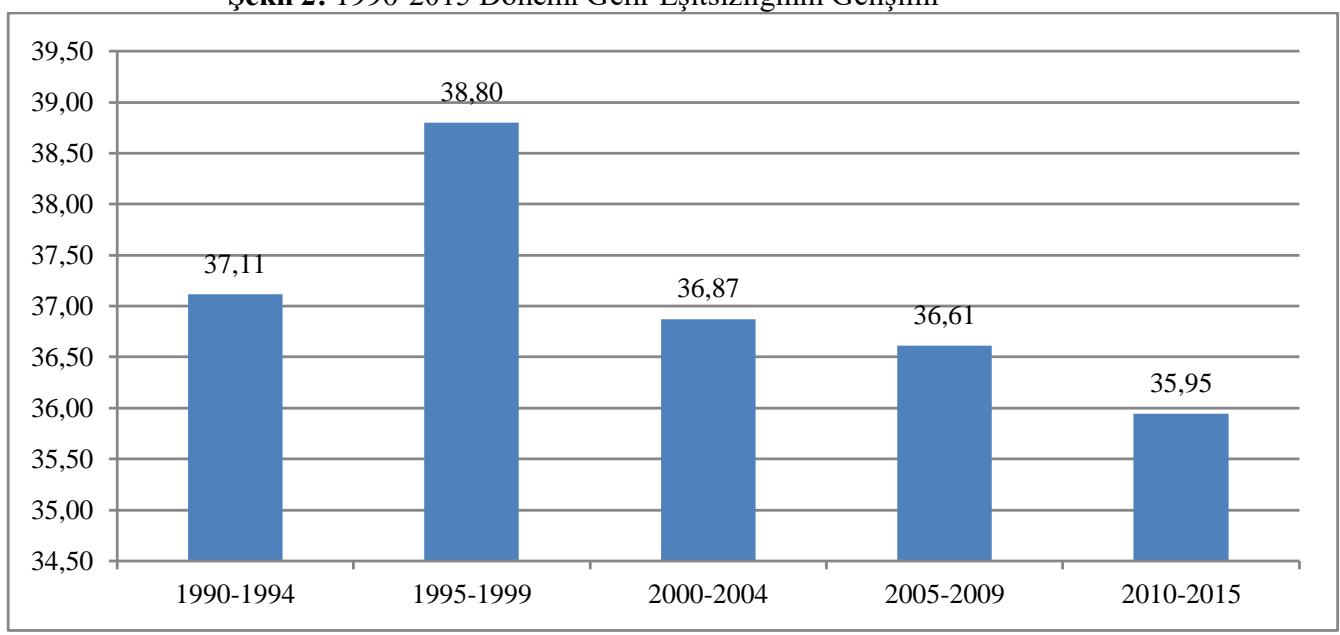

Kaynak: Dünya Bankası’nın 1990-2015 yıllarına ait verileriyle oluşturulmuştur.

Şekil 2 incelendiğinde ilgili ülkelerde gelir eşitsizliğinin 2000'li yıllardan itibaren azalış göstermesine rağmen $35^{\prime}$ in altına düşmediği görülmektedir. Örnekleme dâhil olan ülkelerde, 1995-1999 y1llarında gelir eşitsizliğini arttıran gelişmeler olduğu görülmektedir. Bu eşitsizliğin nedeni ayrıntı düzeyinde ülkeler tek tek incelenerek bulunabilir. Bununla beraber, biz bu çalışmada gelir eşitsizliğinin nedenlerini değil, oluşan eşitsizliklerin politik kutuplaşmayı nasıl etkilediğini araştırmaktayız. Bu ülkelerdeki ilgili dönemdeki gelir eşitsizlikleri başka bir akademik çalışmanın konusunu oluşturur.

\section{B.Yöntem ve Model}

$\mathrm{Bu}$ çalışmada politik kutuplaşmanın belirleyicilerini ortaya koymak için panel veri analizi kullanılmıştır. Panel veri analizi, bireyler, firmalar, ülkeler, hane halk1 gibi birimlere zaman serisi ve yatay kesit verilerini bir araya getirmeye imkân sağlayan bir ekonometrik tekniktir (Hsiao, 2007:6). Bu durum gözlem sayısının artmasina ve serbestlik derecesine sahip olma, birim ve zaman etkilerinin gözlenmesine olanak tanıma gibi avantajlara sahiptir (Woolridge, 2002:452, Tatoğlu, 2013:3). Panel veri analizi güvenilir ve daha etkin tahminlere olanak sağlaması nedeniyle ampirik literatürde yaygın olarak kullanılmaktadır (Hsiao, 2007:2). Ancak, veri setinde eksik gözlemler mevcut olduğundan çalışma dengesiz panel veri seti ile yürütülmüştür. Öte yandan, kullanılacak panel veri tahmin modelleri arasındaki seçim, kullanılan veri setine, kullanılan değişkenlerin birbiriyle olan ilişkilerinin teorik altyapısına ve çeşitli istatistiksel testlere göre de belirlenmektedir.

Çalışmada kullanılan model ilk olarak En Küçük Kareler (EKK) yöntemiyle tahmin edilmiştir. EKK tahmin yönteminin kullanıldığı modellerde genellikle sabit ve tesadüfi etkiler model tahmincileri kullanılmaktadır. Hangi tahmincinin tercih edileceği ise öncelikle veri setinin oluşturulduğu örneklem grubuyla ilişkilidir. Örneğin, veri seti belirli bir örneklem grubundan gelmiş 
gözlemlerden oluşuyorsa sabit etkiler modeli tersine veri seti geniş bir örneklem grubundan rastgele seçilmiş gözlemlerden oluşuyorsa tesadüfi etkiler modeli tercih edileceği varsayılır. Bu varsayımı desteklemek amacıyla söz konusu tahmin modelleri arasında tercih yapmak için literatürde genellikle Hausman (1978) tarafından geliştirilen Hausman test istatistiği kullanılmaktadır. Ancak, modelde, değişkenler arasında ters yönlü bir nedensellik durumunda, parametre tahminleri yanlı ve tutarsız olacağından EKK tahmincisi tutarlı sonuçlar vermeyecektir (Gujarati, 2011:311). Böyle bir içsellik sorununun giderilmesi amacıyla içsel (endojen) değişken yerine araç değişken/değişkenlerden yararlanılarak tutarlı ve yansız parametreler elde edilir (Arı \& Özcan, 2012:161). Bu amaçla gözlem sayısını azaltmamak adına çalışmada iki aşamalı en küçük kareler yöntemi kullanılmaktadır. Öte yandan, iki aşamalı en küçük kareler yönteminde, araç değişkenlerin geçerliliği Sargan testi ile sınanmaktadır. Bu testin boş hipotezi "araç değişkenler geçerlidir" şeklinde olup boşluk hipotezinin kabul edilmesi beklenmektedir.

$\mathrm{Bu}$ çalışma açısından bakıldığında, gelişmekte olan ülkelerde Gini endeksi tüketim verilerine dayanıyor olmasından dolayı politik kutuplaşmanın etkisini sahte bir şekilde azaltabilmektedir. Bu durumlarda Gini endeksi politik kutuplaşmaya karşı içsel olabilmektedir (Lindqvist \& Östling, 2010:551). Ortaya çıkan içsellik sorununu giderebilmek amacıyla bağımlı değişken olan politik kutuplaşmayı açıklayabilecek ancak kutuplaşmayı başka bir kanaldan etkilemeyecek araç değişkenler bularak politik kutuplaşma iki aşamalı olarak analiz edilmeye çalışılmıştır. Çalışmada kullanılmak üzere bu açıklamaya uyan araç değişkenler olarak, Persson ve Tabellini (2001, 2003) çalışmalarında kullanılan "hukuk sistemleri” kullanılmıştır. Bu bağlamda, La Porta et al. (1999) çalışmasında yer alan dört hukuk sistemi (İngiliz Hukuku, Fransız Hukuku, Anglo-Sakson Hukuk Sistemi ve İskandinav Hukuku) kukla olarak kullanılmıştır.

Çalışmada kullanılan model için başta Akdede (2012) çalı̧̧masında kullandığ1 model referans alınmıştır. Ancak, Akdede (2012) çalışmasında partilerin oy dağılımlarına göre hesaplanan kutuplaşma endeksi kullanmıştır. $\mathrm{Bu}$ çalışmada model, Lindqvist ve Östling (2010) çalışmaları da göz önüne alınarak geliştirilmiş ve aşağıdaki tahmin modeli oluşturulmuştur:

$K_{i t}=\beta_{0}+\beta_{1}$ Gini $_{i t}+\beta_{2} G_{i t}+\beta_{3} T_{i t}+\beta_{4} D_{i t}+\beta_{5} C_{i t}+\beta_{6} G e_{i t}+\delta X_{i t}+v_{i}+\varepsilon_{i t}$

\section{Ampirik Bulgular}

Modelde yer alan değişkenlere ilişkin tanımlayıcı istatistikler Tablo 3'de verilmiştir. Analiz döneminde (1990-2015), ülkelerin ortalama politik kutuplaşma değeri 2,78 düzeyinde gerçekleşmiştir. Politik kutuplaşmanın en yüksek olduğu ülkeler 3,6 seviyesiyle Meksika ve Türkiye iken politik kutuplaşmanın en düşük olduğu ülke ise 1,91 seviyesi ile Pakistan'dır. Gelir eşitsizliğinin en yüksek olduğu ülke 70.3 ile Zimbabve iken en düşük gelir eşitsizliğine sahip ülke ise 16.6 ile Azerbaycan'dır. Öte yandan, ilgili dönemde kamu tüketim harcaması en düşük \%1.14 oranıyla Nijerya iken \%26.4 ile İsveç en yüksek kamu tüketim harcaması yapan ülke konumundadır. Dini bölünmenin en düşük olduğu ilk üç ülke Fas 
$(0,003)$, Türkiye $(0,004)$ ve Cezayir $(0,009)$ iken en yüksek dini bölünmeye sahip ilk üç ülke ise Güney Afrika $(0,86)$, Avustralya $(0,82)$ ve Amerika Birleşik Devletleri $(0,82)$ 'dir.

Tablo 3: Tanımlayıcı İstatistikler

\begin{tabular}{cccrrr}
\hline Değişken Adl & Gözlem & Ortalama & Std.Hata & \multicolumn{1}{c}{ Min. } & Max. \\
\hline \hline Politik Kutuplaşma & 174 & 2.78 & 0.35 & 1.92 & 3.6 \\
Gini & 273 & 37.03 & 9.05 & 16.6 & 70.3 \\
GSYIH & 301 & 11280.98 & 15799.65 & 154.70 & 94151.16 \\
Demokrasi Seviyesi & 294 & 5.34 & 5.59 & -9 & 10 \\
Kamu Tüketim Harcamasi & 300 & 15.43 & 5 & 1.14 & 26.49 \\
Dini Çeşitlilik & 305 & 0.44 & 0.23 & 0.00 & 0.86 \\
Gelişmekte & 305 & 0.59 & 0.49 & 0 & 1 \\
Fransiz Hukuk Sistemi & 305 & 0.32 & 0.47 & 0 & 1 \\
İngiliz Hukuk Sistemi & 305 & 0.24 & 0.43 & 0 & 1 \\
Anglo-Sakson Hukuk & 305 & 0.31 & 0.46 & 0 & 1 \\
Sistemi & 305 & 0.04 & 0.21 & 0 & 1 \\
İskandinav Hukuk Sistemi & & & & 0 & 1 \\
\hline
\end{tabular}

Tablo 4'de temel ampirik bulguları vermesi açısından önce EKK tahmini sonra da araç değişken kullanılarak yapılan İki Aşamalı En Küçük Kareler Yönteminin sonuçları sunulmuştur. Panel veri sonuçlarına göre, her iki modelin de istatistiki olarak anlamlı olduğu görülmektedir. Ayrıca, araç değişkenlerin geçerliliğini sınamak amacıyla Sargan testi uygulanmış ve 2EKK tahmin modeli için geçerli olduğu tespit edilmiştir.

\begin{tabular}{|c|c|c|}
\hline \multicolumn{3}{|c|}{ Bağımlı Değişken: Politik Kutuplaşma } \\
\hline Bağımsız Değişken & $\begin{array}{l}\text { EKK (1) } \\
\text { (z-stat.) }\end{array}$ & $\begin{array}{l}\text { 2EKK (2) } \\
\text { (z-stat.) }\end{array}$ \\
\hline Gini & $\begin{array}{c}0.01 * * * \\
(4.63)\end{array}$ & $\begin{array}{c}0.01 * * \\
(2.49)\end{array}$ \\
\hline G & $\begin{array}{c}-5.23 * * \\
(-2.52)\end{array}$ & $\begin{array}{c}-5.47 * * * \\
(-2.76)\end{array}$ \\
\hline $\mathrm{T}$ & $\begin{array}{c}-0.01 * * * \\
(-2.70)\end{array}$ & $\begin{array}{c}-0.01 * * * \\
(-3.10)\end{array}$ \\
\hline $\mathrm{D}$ & $\begin{array}{c}0.01 * * * \\
(3.49)\end{array}$ & $\begin{array}{c}0.02 * * * \\
(4.13)\end{array}$ \\
\hline Ç & $\begin{array}{c}-0.23 * * \\
(-2.04)\end{array}$ & $\begin{array}{c}-0.20 * * \\
(-2.16)\end{array}$ \\
\hline $\mathrm{Ge}$ & $\begin{array}{c}0.10 \\
(1.45)\end{array}$ & $\begin{array}{c}0.12^{* * *} \\
(2.08)\end{array}$ \\
\hline Sabit & $\begin{array}{c}2.49 * * * \\
(14.68)\end{array}$ & $\begin{array}{c}2.57 * * * \\
(12.34)\end{array}$ \\
\hline Gözlem & 160 & 160 \\
\hline R-kare & 0.56 & 0.43 \\
\hline Wald istatistiği & $85.94 * * *$ & $100.88 * * *$ \\
\hline Hausman testi & 0.80 & \\
\hline Durbin/Wu-Hausman & & 0.04 \\
\hline Sargan İstatistiği (p-value $)^{2}$ & & 0.43 \\
\hline
\end{tabular}

Not: ******* sirasıyla $\% 1, \% 5$ ve $\% 10$ anlamlılık düzeylerini göstermektedir.

2 Sargan test istatistiği araç değişkenlerin geçerliliğini test etmek için kullanılmıştır. Test istatistiği sonucu pdeğeri, "araç değişkenler geçerli değildir" H0 hipotezinin reddedildiğini, yani araç değişkenlerin geçerli olduğunu göstermektedir. 
EKK ve 2EKK modellerinin tahmin sonuçları değerlendirildiğinde tahmin modellerinin yaklaşık olarak benzer sonuçlar verdiği görülmektedir. Her iki tahmin modelinin sonuçlarına göre; gelir eşitsizliği politik kutuplaşma üzerinde istatistiki olarak anlamlı ve pozitif bir etkiye sahiptir. Yani, gelir eşitsizliği arttıkça politik kutuplaşma artmaktadır. GSYIH, kamu tüketim harcaması, dini çeşitlilik ve demokrasi düzeyinin politik kutuplaşma üzerinde güçlü birer açıklayıcı etkiye sahip olduğu görülmektedir. GSYIH, kamu tüketim harcaması ve dini çeşitlilik politik kutuplaşma üzerinde istatistiki olarak anlamlı ve negatif bir etkiye sahipken, demokrasi düzeyi pozitif bir etkiye sahiptir. Yani, bir ülkede milli gelir arttıkça politik kutuplaşma azalmaktadır. Kamu tüketim harcamalarındaki artış da politik kutuplaşmayı azaltmaktadır. Ancak, demokrasi düzeyi yüksek ülkelerde politik kutuplaşmanın yüksek olduğu görülmektedir.

\section{SONUÇ}

Devlet, toplumsal ve tarihsel koşullara göre zaman içinde farklı biçim ve nitelikler kazanmıştır. Dahası, devletler ekonominin içinde bulunduğu koşullara göre üstlenmiş oldukları görev ve fonksiyonlar çerçevesinde zaman zaman iktisadi ve sosyal yapıya müdahalelerde bulunmuşlardır. Ancak, devletlerin bu müdahale şekillerinde yalnızca ekonomik faktörler etkili olmamış politik düşünceler de söz konusu müdahaleleri etkilemiştir. Bunun nedeni, bir ülkede sosyo-ekonomik kutuplaşmanın seçmenlerdeki bölünmeleri arttırarak politik kutuplaşmaya yol açması ve bu durumun devletin kamu politikaları üzerinde etkili olacağı varsayılmasıdır.

Bu çalışmada 61 ülkenin 1990-2015 dönemine ait 5'er yıllık ortalama verileri kullanılarak politik kutuplaşmanın belirleyicileri ampirik olarak araştırılmıştır. Kutuplaşma değişkeni, Dünya Değerler Anketi veri tabanındaki "government responsibility" anket sorusu standart sapmasıyla hesaplanmıştır. Bu değişkenin yüksek olduğu toplumlarda bireyci eğilimlerin söz konusu olduğu ancak düşük olduğu toplumlarda ise insanların daha çok devletçi davrandığı varsayılmaktadır.

Analiz sonuçlarına göre, politik kutuplaşmanın gelir eşitsizliği ile arttığ 1 görülmektedir. Yani, gelir dağılımından olumsuz etkilenenler devletin müdahalesini isterken geliri artan kesim devletten yeniden dağıtım yapmasını istememektedir. Devletin ekonomik büyüklügünü ifade eden kamu tüketim harcamaları ile politik kutuplaşma arasında ise anlamlı ve negatif bir ilişki bulunmuştur. Kamu tüketim harcamaları arttıça, politik kutuplaşma azalmaktadır. Analiz sonuçlarından çıkan bir diğer sonuç da yüksek demokrasi düzeyine sahip ülkelerde politik kutuplaşmanın arttığ 1 ve gelir eşitsizliği veri iken, milli gelirin politik kutuplaşmayı azalttığıdır. Demokratik ülkelerde, politik kutuplaşma olmasına olanak tanınmaktadır. Tahmin edileceği gibi diktatörlüklerde, politik kutuplaşma yerine tek politik görüş ve uygulama vardır. Öte yandan, dini çeşitlilik gibi kültürel farklılıkların; gelir eşitsizliği, kişi başı GSYİH ve kamu tüketim harcamaları gibi ekonomik faktörler kadar önemli olduğu tespit edilmiştir. 


\section{KAYNAKÇA}

Akdede, S. H. (2010). Do More Ethnically and Religiously Diverse Countries Have Lower Democratization?. Economics Letters, 106 (2), 101-104.

Akdede, S. H. (2012). Income Inequality and Political Polarization and Fracturalization: An Empirical Investigation of Some European Countries. Bulletin of Economic Research, 64 (1), 20-30.

Alesina, A., Devleeschauwer, A., Easterly, W., Kurtat, S. \& Wacziarg, R. (2002). Fractionalization. Journal of Economic Growth, 8 (2), 155-194.

Alt, J. E. \& Lassen, D. D. (2006). Transparency Political Polarization and Political Budget Cycles in OECD Countries. American Journal of Political Science, 50 (3), 530-550.

Arı, A. \& Özcan, B. (2012). Hollanda Hastalığı: Gelişmekte Olan Ülkeler Üzerine Bir Uygulama. Sosyoekonomi, 18 (18), 153-172.

Brown, D. S., Touchton, M. \& Whitford, A. (2011). Political Polarization as a Constraint on Corruption: A Cross-national Comparison. World Development, 39 (9), 1516-1529.

Azomahoua, T. T. \& Diene, M. (2012). Polarization patterns in economic development and innovation. Structural Change and Economic Dynamics, 23 (4), 421- 436.

Campante, F. R. \& Hojman, D. A. (2013). Media and Polarization Evidence from the Introduction of Broadcast TV in the United States. Journal of Public Economics, 100, 79-92.

Çakır, Ö. (2002). Sosyal Dışlama. Dokuz Eylül Üniversitesi Sosyal Bilimler Enstitüsü Dergisi, 4(5), 83-105.

Duclos, J.-Y., Esteban, J. \& Ray, D. (2004). Polarization: concepts, measurement and estimation. Econometrica, 72 (6), 1737-1772.

Esteban, J. \& Ray, D. (2011). Linking Conflict to Inequality and Polarization. American Economic Review, 101 (4), 1345-1374.

European Values Study Group and World Values Association (2006), European and World Values Surveys Wave 2 1990-1994, Version 2014-04-29, http://www.worldvaluessurvey.org/WVSDocumentationWV2.jsp (Erişim: 17.06.2019).

European Values Study Group and World Values Association (2006), European and World Values Surveys Wave 3 1995-1998, Version 2014-04-09, http://www.worldvaluessurvey.org/WVSDocumentationWV3.jsp (Erişim: 17.06.2019).

European Values Study Group and World Values Association (2006), European and World Values

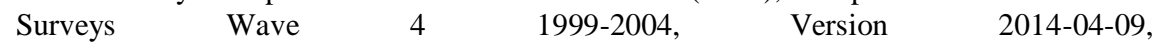
http://www.worldvaluessurvey.org/WVSDocumentationWV4.jsp (Erişimi: 17.06.2019).

European Values Study Group and World Values Association (2006), European and World Values Surveys Wave 5 2005-2009, Version 2014-04-09, http://www.worldvaluessurvey.org/WVSDocumentationWV5.jsp (Erişim: 17.06.2019).

European Values Study Group and World Values Association (2006), European and World Values Surveys Wave 6 2010-2014, Version 2014-04-09, http://www.worldvaluessurvey.org/WVSDocumentationWV6.jsp (Erişim: 17.06.2019).

Frye, T. (2002). The Perils of Polarization: Economic Performance in the Postcommunist World. World Politics, 54 (3), 308-337.

Grechyna, D. (2016). On the Determinants of Political Polarization. Economics Letters, 144 (C), $10-14$.

Gujarati, D. N. (2011). Econometric By Exemple, Boston: The Mc-Graw-Hill Companies.

Hacker, J. S. (2004). Privatizing Risk Without Privatizing the Welfare State: the Hidden Politics of Social Policy Retrenchment in the United States. The American Political Science Review, 98 (2),243-260.

Hsiao, C. (2007). Panel Data Analysis-Advantages and Challenges. Test: An Official Journal of the Spanish Society of Statistics and Operations Research, 16 (1), 1-22.

Kotera, G. \& Okada, K. (2017). How does democratization affect the composition of government expenditure?. Journal of Economic Behavior \& Organization, 137 ( C), 145-159.

Lindqvist, E. \& Östling, R. (2010). Political Polarization and the Size of Government. The American Political Science Review, 104 (3), 543-565. 
Londregan, J. B.\& Poole, K. T. (1996). Does High Income Promote Democracy? World Politics, 49 (1), 1-30.

McCarty, N., Poole, K. T.\& Rosenthal, H. (2006). Polarized America: The Dance of Ideology and Unequal Riches, MIT Press.

McCright, A. M., Xiao, C. \& Dunlap, R.E. (2014). Political polarization on support for government spending on

environmental protection in the USA, 1974-2012. Social Science Research, 48, 251-260.

Meltzer, A. H. \& Richard, S. F. (1981). A Rational Theory of tha Size of Government. Journal of Political Economy, 89 (5), 914-927.

Montalvo, J. G.\& Reynal-Querol, M. (2005). Ethnic Polarization, Potential Conflict, and Civil Wars. The American Economic Review, 95 (3), 796-816.

Profeta, P., Puglisi, R. \& Scabrosetti, S. (2013). Does Democracy Affect Taxation and Government Spending? Evidence from Developing Countries. Journal of Comparative Economics, 41 (3), 684-718.

Rehm, P. (2011). Risk inequality and the polarized American electorat. British Journal of Political Science, 41( 2), 363-387.

Tatoğlu, Y. F. (2013). Panel Veri Ekonometrisi: Stata Uygulamall, (İkinci baskl), İstanbul: Beta Yayınları.

Testa, C. (2012). Is Polarization Bad?. European Economic Review, 56 ( 6), 1104-1118.

Wooldridge, J. M. (2002). Econometric Analysis of Cross Section and Panel Data, Cambridge: The MIT Press.

World Bank (2017), World Development Indicators 2017, Washington, DC: World Bank.

Zhang, X. \& Kanbur, R. (2001). What differences do polarization measures make? An application to China. Journal of Development Studies, 37 (3), 85-98.

\section{SUMMARY}

The purpose of this is to understand the possible determinants of political polarization. Therefore, this paper empirically investigates the determinants of political polarization. First political polarization is defined and then measured to be used in the regression analysis. Political polarization is derived from World Values Survey ( WVS) database. It is measured as standard deviation of responses to the question "what is role for government". When we look at the literature, it is seen that political polarization can be handled in different ways and that the indices created depend on the factors put forward. In this context, alternative methods of measuring political polarization have emerged. To calculate political polarization, the "government responsibility" question is used in the World Values Research (WVS) database. The standard deviation of this survey question is taken as our measure of poltical polarization. WVS consists of nationally represented survey questions conducted in five-year periods (waves) and includes answers reached based on face-to-face interviews with approximately 1,000 people per country. As far as we know, there is no study that measures political polarization in Turkey with the help of WVS survey data, so it is aimed. Also, size of government, income distribution, level of democracy, GDP per capita and religious fractionalization are the main independent variables along with other controlling variables.

In this study, the factors affecting political polarization were tried to be determined by using the 5-year average data of 61 countries in the WVS database for the period 1990-2015. The reason the data set was created 5-years average is 
that the political polarization data is organized 5 years average. In addition, the periods and countries mentioned in the study were selected based on the availability of data from the World Values Survey (WVS) database. However, these countries are different in socio-economic and demographic characteristics, geographical conditions and many other aspects and show a heterogeneous structure.

Panel data analysis was used in this study. The model used in the study was first estimated by Least Squares (OLS) method. However, in the model, in the case of an inverse causality between variables, the OLS estimator will not yield consistent results as parameter estimates will be biased and inconsistent. In order to solve such an endogeneity problem, consistent and neutral parameters are obtained by using instrumental variables/variables instead of intrinsic (endogenous) variables. For this purpose, in order not to reduce the number of observations, two-stage least squares method is used in the study. Results of regressions analysis indicates that increased income inequality increases political polarization. That is, those who are negatively affected by the distribution of income want the intervention of the state, while those who have high income do not want the redistribution of income from the state. In addition, results of our empirical indicates that increased governemt size reduces the political polarization. Another conclusion from the analysis is that in countries with high levels of democracy, political polarization is increasing with income inequality, while countries with higher GDP per capita have lower political polarization. On the other hand, cultural differences such as religious fractionalization were found to be as important as economic factors such as income inequality, GDP per capita and government consumption expenditures. 